\title{
HISTORIES Spinal cord injury in Vietnamese combat
}

\author{
SA Jacobson* and E Bors \\ Spinal Cord Injury Service of the Veterans Administration Hospital, Long Beach, California, and the Department of \\ Surgery, University of California, School of Medicine, Los Angeles, California
}

This report deals with the experience gained by observation and treatment of 114 Vietnamese combat injuries from December 1965 to April 1969. The report covers all aspects of rehabilitation, medical, physical and socio-economic.

Spinal Cord (2001) 39, 340-350

\section{Methods and materials}

The data presented were collected via examination of charts only (both in-patient and out-patient) in 60 instances. In 54 instances charts were utilised and the patient was also interviewed. Correspondence was used when appropriate to fill in data or bring them up to date. No patient's record was so unsatisfactory as to preclude inclusion in the study. All of these patients are service connected with government compensation. Their paraplegia demanded close medical supervision which was carried out in this government institution.

Since December 1965 about 250 new patients with spinal cord injury considered 'Vietnam conflict' have been treated at the Long Beach Veterans Administration Hospital. This survey concerns itself only with the actual combat injuries as the non-combat do not differ from peacetime civilian paraplegics. The combat injuries differ in $(a)$ severity of injury (often multiple wounds); (b) problems regarding first aid and evacuation; (c) they have been shown to behave differently in regard to complications and course (Bors, 1951; Comarr et al 1962) in previous studies.

Age distribution of patients is shown in the following Table 1.

As can be seen, 80 patients were under 24 years of age $(70 \%)$, and only 11 were over $30(9.6 \%)$. In the latter group were patients who were injured in supervisory positions (bunker building: two), or were non-combatants (chaplain: two; mail delivery: one), etc.

Table 2 illustrates the level distribution.

The level indicated refers to the neurological level found on neurological admission examination. The lowest normally functioning segment is designated as the patient's 'level'. Functionally only the segmental level is important rather than the vertebral level which is still often quoted. As has been pointed out (Michaelis, 1968; Bunts, 1967) a fracture of T10 to T12 may produce a complete or incomplete lesion below T9 or a cauda equina lesion with or without an

*Permanent address: Jewish General Hospital, Department of Urology, Cote des Neige and Van Horne, Montreal 25, Canada epiconal lesion below L3 or L4. The orthopaedic classification fails to clarify the lesion. This statement may be extended in view of the fact that we have seen lesions as high as T6 with complete distal flaccidity. This is believed to be on a vascular basis.

The mechanism of injury is indicated in Table 3.

Shell fragments include pieces of metal from landmines, mortars, grenades or booby traps. Blast injury with the victim thrown for a varying distance and landing on the back, buttocks, or feet often led to compression fractures as did vehicle crashes. 'Vehicle crash' referred to a helicopter in five instances.

\section{Observations}

The majority of these patients had multiple system injuries and accompanying shock was common. Evacuation was rapid to a well-equipped field hospital or hospital ship. Often more immediately vital injuries than the spinal cord involvement were by necessity first treated. Table 4 presents data on these major injuries.

Most of these major injuries were accompanied by minor lacerations and soft tissue shell fragment wounds particularly of the extremities.

The definitive emergency treatment extended to the above injuries is shown in Table 5 .

There were six patients who had laparotomies with completely negative intra-abdominal findings. The resections of colon were formal left or right hemicolectomies with ileo-transverse colostomy performed. There were no injuries of the rectum.

Seventy-seven of the 114 patients $(67 \%)$ had major injuries in addition to the spinal cord damage.

The major genito-urinary injuries are presented in Table 6 . These are presented separately because of the fact that in following spinal injury patients accurate information regarding the original post-injury state of the urinary tract is so vital.

As is noted no cervical or high thoracic injury sustained a urinary tract wound. There were in this series no genital wounds of more than minor significance. 
The therapy necessary in these injuries is shown in Table 7 .

The uretero-ureteral anastomosis failed with extravasation and delayed nephrectomy was necessary.

Table 1

\begin{tabular}{lc}
\hline Age & Number \\
\hline$<20$ & 15 \\
$20-22$ & 40 \\
$22-24$ & 25 \\
$24-26$ & 12 \\
$26-28$ & 7 \\
$28-30$ & 4 \\
$>30$ & 11 \\
\hline
\end{tabular}

Table 2 Level and extent of lesion

\begin{tabular}{lcc}
\hline & Complete & Incomplete \\
\hline C & 10 & 5 \\
T1 - T6 & 19 & 7 \\
T7-T12 & 27 & 9 \\
L-S & 23 & 14 \\
\hline
\end{tabular}

Table 3 Mechanism of injury

\begin{tabular}{|c|c|c|c|c|c|}
\hline & Bullet & $\begin{array}{c}\text { Shell } \\
\text { fragments }\end{array}$ & Blast & $\begin{array}{l}\text { Vehicle } \\
\text { crash }\end{array}$ & Other \\
\hline $\mathrm{C}$ & 9 & 4 & 1 & 1 & \\
\hline $\mathrm{T} 1$ - T6 & 20 & 6 & 1 & & \\
\hline $\mathrm{T} 7-\mathrm{T} 12$ & 12 & 16 & 5 & 1 & $\begin{array}{l}2 \text { (bunker } \\
\text { collapse) }\end{array}$ \\
\hline L-S & 16 & 7 & 6 & 5 & $\begin{array}{c}1 \text { (elevator } \\
\text { sabotage) } \\
1 \text { (hit by } \\
\text { helicopter) } \\
1 \text { (parachute } \\
\text { jump) }\end{array}$ \\
\hline
\end{tabular}

Table 8 presents data on frequency of laminectomy and correlation of surgical and 'late' clinical findings. Greater than two-cord segments or obvious gross discrepancy are indicated by 'findings that do not correlate'. This reiterates World War II experience that laminectomy and clinical findings do not always correlate.

In this series 107 patients had a laminectomy with the findings correlating in 72 or $67 \%$ In some caes correlation of clinical and surgical findings was not possible due to failure to open the dura or an inadequate record.

Wound infection in the laminectomy incision occurred in six patients, meningitis was documented in four cases, dural cutaneous fistula developed in two and grand mal seizures occurred in two of the patients with meningitis.

In regard to complications during the follow-up period ( 2 months to 3 years and 4 months) it can be stated that they were predominantly G.U.; however, decubiti and pain were frequent and troublesome. Table 9 presents frequency data on decubiti, pain, and dysreflexia. This last, observed by Head and Riddoch (1917), Guttmann and Whitteridge (1947), and Bors and French (1952) is a well-known syndrome occurring in cervical and high thoracic lesions.

The discomfort in the patients with UMN lesions was described usually as burning, crushing, or tingling and in the patients with LMN lesions as shooting or electric; exceptions were noted.

Genito-urinary complications were numerous, the most frequent being infection, calculosis, hydronephrosis, and epididymitis. Data on these, as well as reflux, penoscrotal problems, ureterectasis, and 'pseudopapillomata', are presented in Tables 10 and 11.

\section{Calculosis}

The increased prevalance of renal calculi on the right side has been confirmed (Comarr et al 1962). There were $11.4 \%$ of our patients who developed renal calculi

Table 4 Major injury (non-G.U.)

\begin{tabular}{|c|c|c|c|c|c|c|c|}
\hline & $\begin{array}{l}\text { Gastro-intestinal } \\
\text { tract }\end{array}$ & Spleen & Liver & Chest & $\begin{array}{l}\text { Extrem. or } \\
\text { pelvis }\end{array}$ & Vasc. & Misc. \\
\hline $\mathrm{C}$ & & & & 4 & 1 & 1 & $\begin{array}{l}1 \text { (Skull frac.) } \\
1 \text { (Facial inj.) } \\
1 \text { (Laryng. lacer.) }\end{array}$ \\
\hline $\mathrm{T} 1-\mathrm{T} 6$ & 2 & & & 17 & 5 & 2 & $\begin{array}{l}1 \text { (Trach. lacer.) } \\
3 \text { (Brach. plex.) } \\
1 \text { (Brain inj.) }\end{array}$ \\
\hline $\mathrm{T} 7-\mathrm{T} 12$ & 3 & 5 & 1 & 18 & 2 & 2 & $\begin{array}{l}3 \text { (Lacer, diaph.) } \\
1 \text { (Facial inj.) } \\
1 \text { (Brain inj.) } \\
1 \text { (Periph. nerve) }\end{array}$ \\
\hline L-S & 13 & 1 & 3 & 4 & 7 & 1 & $\begin{array}{l}2 \text { (Severe burn) } \\
1 \text { (Periph. nerve) } \\
1 \text { (Facial inj.) }\end{array}$ \\
\hline
\end{tabular}


Table 5 Emergency therapy (non-G.U.)

\begin{tabular}{|c|c|c|c|c|}
\hline Gastro-intestinal tract & Spleen & Chest & Liver & Ext. and/or pelvis \\
\hline $\begin{array}{l}\text { Esophagus } \\
\quad \text { Lacer. sut.: } 2\end{array}$ & Splenectomy: 5 & $\begin{array}{l}\text { Thoracotomy and/or } \\
\text { tube insert.: } 39\end{array}$ & lacer. sut.: 4 & $\begin{array}{l}\text { Arm amputation: } 1 \\
\text { Debrid. and closure: } 3 \\
\text { Fracture aligned: } 9\end{array}$ \\
\hline $\begin{array}{l}\text { Small bowel } \\
\quad \text { Resection: } 3 \\
\text { Lacer. repair: } 2\end{array}$ & & & & \\
\hline $\begin{array}{l}\text { Colon } \\
\text { Colostomy: } 9 \\
\text { Resection: } 4 \\
\text { Lacer. repair: } 2\end{array}$ & & & & \\
\hline
\end{tabular}

Table 6 Major injury (G.U.)

\begin{tabular}{lccccc}
\hline & \multicolumn{2}{c}{ Renal } & Blad. & \multicolumn{2}{c}{ Uret. } \\
& Rt. & Lt. & rupt. & Rt. & Lt. \\
\hline C & - & - & - & - & - \\
T1-T6 & - & - & - & - & - \\
T7-T12 & 1 & 7 & - & - & - \\
L-S & 5 & 3 & 1 & 1 & - \\
\hline
\end{tabular}

Table 7 Emergency therapy (G.U.)

\begin{tabular}{lccc}
\hline & Renal & & Other \\
\hline Neph. & Part. neph. & $\begin{array}{c}\text { Repair and } \\
\text { drainage }\end{array}$ & $\begin{array}{c}\text { Uretero-uret. } \\
\text { anastom.: } 1\end{array}$ \\
8 & 1 & 7 & $\begin{array}{c}\text { Bl. rupture } \\
\text { drainage } \\
\text { suprapub.: } 1\end{array}$ \\
\hline
\end{tabular}

Table 8 Laminectomy

\begin{tabular}{lcccc}
\hline & Done & Not done & $\begin{array}{c}\text { Findings } \\
\text { correlate }\end{array}$ & $\begin{array}{c}\text { Findings do } \\
\text { not correlate }\end{array}$ \\
\hline C & 14 & 1 & 10 & 3 \\
T1-T6 & 25 & 1 & 14 & 5 \\
T7-T12 & 33 & 2 & 22 & 5 \\
L-S & 35 & 2 & 26 & 2 \\
\hline
\end{tabular}

Table 9

\begin{tabular}{lcccc}
\hline \multicolumn{5}{c}{ Pain } \\
& Decubiti & UMN & LMN & Dysreflexia \\
\hline C & 8 & 3 & - & 4 \\
T1-T6 & 13 & 7 & - & 2 \\
T7-T12 & 15 & 8 & 10 & - \\
L-S & 15 & 1 & 21 & - \\
\hline
\end{tabular}

over the 3 years and 4 months period (Bunts et al 1967; Bors, 1951). Ureteral calculi were found on the right side in two cases and left side in one case. All demanded operative intervention. If these are added to the renal calculi, the occurrence rate rises to $13 \%$ of our patients.

\section{Infection}

Cultures were almost all on catheter specimens and rarely mid-streams. The latest culture available was considered. Many patients who were positive by this criterion had previously had negative cultures. The organisms cultured in 'heavy' growth were: Proteus, 67 patients; Pseudomonas, 29 patients; Aerobacter aerogenes, 21 patients; E. coli, 13 patients; Paracolon, eight patients; and Klebsiella, one patient. In some cases mixed growth occurred.

Reflux

The number of cases of reflux in this group was too small to consider further.

Bladder calculi were all 'infected' stones of the mixed type associated with catheter drainage or a degree of residual urine.

Penoscrotal problems have been eliminated by early intermittent catheterisation (Guttmann et al 1966). Our patients could not be treated in this way because of combat conditions and 8.8\% developed abscess, diverticulum, or fistula.

\section{Epididymitis}

In addition to the figures given in Table 11, two patients developed this complication without the involved side being clearly stated.

\section{'Pseudopapillomata'}

We observed seven patients with excrescences which were diagnosed histologically in five cases as pseudopapillomata and in two cases as squamous carcinoma Grade I and squamous carcinoma Grade II, respectively, of the urethra. 
Table 10 Complication (G.U.) upper tract

\begin{tabular}{|c|c|c|c|c|c|c|c|c|c|c|}
\hline & \multicolumn{2}{|c|}{ Calculosis renal } & \multicolumn{2}{|c|}{ Infection } & \multicolumn{2}{|c|}{ Reflux } & \multicolumn{2}{|c|}{ Hydroneph. } & \multicolumn{2}{|c|}{ Ureterect. alone } \\
\hline & Rt. & Lt. & Pos. & Neg. & Rt. & Lt. & Rt. & $L t$. & Rt. & Lt. \\
\hline $\mathrm{C}$ & 5 & 1 & 10 & 4 & - & - & - & - & - & - \\
\hline T1 - T6 & 1 & 1 & 21 & 4 & 1 & 1 & 2 & 2 & - & - \\
\hline $\mathrm{T} 7-\mathrm{T} 12$ & 1 & 1 & 29 & 4 & 2 & 2 & 5 & 3 & 2 & 1 \\
\hline L-S & 1 & 2 & 25 & 9 & - & 1 & 4 & 4 & 1 & - \\
\hline
\end{tabular}

Table 11 Complications (G.U.) lower tract

\begin{tabular}{lccccccc}
\hline & Bladder & & P-S & \multicolumn{2}{c}{ Epididymitis } & \multicolumn{2}{c}{ 'Pseudopap.' } \\
& caculi & Abscess & Divert & Fistula & Rt. & Lt. & Blad. \\
\hline C & 6 & - & - & - & - & - & - \\
T1-T6 & 13 & - & 1 & 2 & 2 & 2 & 2 \\
T7-T12 & 15 & 1 & 2 & - & 2 & 2 & - \\
L-S & 22 & - & - & 4 & 2 & 2 & - \\
\end{tabular}

Additional urological complications incurred were: severe 'catheter' urethritis, two patients; balanitis (all on condoms), six patients; phimosis, one patient; venereal warts (proven by biopsy), one patient; paraphimosis, one patient; severe scrotal dermatitis, one patient; ulcers of the glans, four patients (on condoms); scrotal abscess, one patient. One patient developed an acute renal failure requiring hemodialysis prior to his admission to our facility. One patient had renal papillary necrosis, and one patient developed a right perinephric abscess 21 months post-injury. He had had a partial nephrectomy on the affected side immediately post injury.

The non-urological complications, many of which occurred prior to arrival at the Long Beach VA Hospital, are listed below. There are a reflection of the severity of injury and generally are those to be expected with the surgical treatment of trauma.

- G.I. bleeding: four patients

- Thrombophlebitis: seven patients

- Pulmonary embolus: two patients

- Deafness: one patient

- Wound infection: four patients

- Enterocolitis: one patient

- Fracture femur: one patient

- Gram-negative sepsis: three patients

- Cardiac arrest: three patients

- Bowel obstruction: four patients

- Empyema with bronchopleural fistula: one patient

- Serum hepatitis: two patients

- Diabetes: one patient

- Gynecomastia: two patients

Urological rehabilitation aimed for renal preservation and bladder balance. Table 12 presents data on the percentage of patients achieving a catheter free state.

The cause of regression, ie reason to return to indwelling catheter drainage, was evidence of deterioration of the upper tracts or failure to maintain bladder balance. This was discovered on routine IVP re-examination and/or cystogram; or re-examination
Table 12

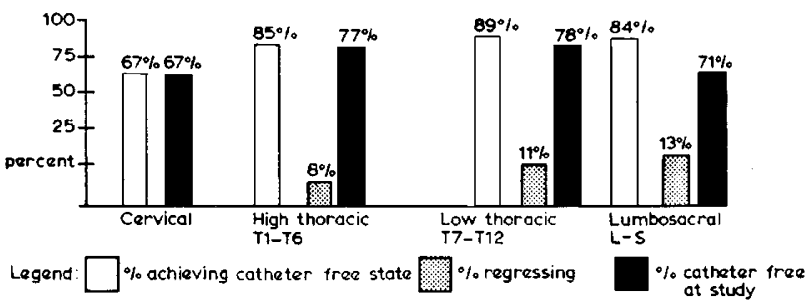

indicated by clinical symptomatology. The most common reason was a significant degree of ureteral and/or pyelocalyceal dilatation. Catheters replaced for short periods for balanitis, penile lesions, to support ureteral catheters for renacidin therapy were not included.

Table 13 shows the time period necessary for each group to become catheter free. The term catheter free implies a 'balanced' bladder function (Bors, 1948).

Eleven and a half per cent of our patients became catheter-free within 3 months of injury; $30.9 \%$ between 3 and 6 months; $23.0 \%$ between 6 and 9 months; $13.2 \%$ between 9 and 12 months; and $6.1 \%$ over 1 year. This yields a total of $84.7 \%$, achieving a balanced state with $9.7 \%$ regressing. At time of study $75.0 \%$ were catheter-free.

The procedures used to facilitate bladder balance in those that did not recover function spontaneously are outlined in Table 14.

The blocks used were: (a) mucosal anaesthesia using a surface application of pontocaine $1 / 4 \%$ in the bladder, xylocaine in the urethra, and nupercaine in the rectum (Bors, 1964); (b) pudendal blocks using $1 / 4 \%$ xylocaine to block gamma fibres progressing as necessary to a $1 \%$ solution. The TUR was done as recommended by Comarr (1959).

Delayed intermittent catheterisation is currently being practised in this Centre. This may be an 
Table 13 Time to become catheter free

\begin{tabular}{|c|c|c|c|c|c|c|c|}
\hline & 3 months & $3-6$ months & $6-9$ months & $9-12$ months & 1 year & Nil & Regression \\
\hline C & 3 & 4 & 2 & 1 & & 5 & \\
\hline $\mathrm{T} 1-\mathrm{T} 6$ & 1 & 9 & 7 & 2 & 3 & 4 & 2 \\
\hline $\mathrm{T} 7-\mathrm{T} 12$ & 4 & 14 & 9 & 4 & 2 & 4 & 4 \\
\hline L-S & 5 & 8 & 8 & 8 & 2 & 4 & 5 \\
\hline Total & 13 & 35 & 26 & 15 & 7 & 17 & 11 \\
\hline
\end{tabular}

Table 14

\begin{tabular}{lccc}
\hline & Blocks & TUR & Sphincterotomy \\
\hline C & 2 & 0 & - \\
T1 - T6 & 1 & 2 & - \\
T7-T12 & 2 & 4 & - \\
L-S & 4 & 3 & 1 \\
\hline
\end{tabular}

additional factor in hastening bladder recovery. In 28 patients of this study this was utilised. Table 15 presents data pertinent to the delayed intermittent catheterisation programme. It should be noted that catheterisation began every $4 \mathrm{~h}$, progressing to every $8 \mathrm{~h}$, every $12 \mathrm{~h}$, to a Q24-h schedule. This, in fact, gave an accurate check regarding residual urine.

In the cervical complete group one patient was not successfully voiding by 90 days on the programme and was considered an 'unsuccessful' result. The 90-day figure was arbitrarily chosen. In the T1-T6 incomplete and L-S complete groups one patient is still on the programme and so not fully evaluated. Twentythree developed balanced bladders, three of whom regressed. One patient required a TUR; two patients, pudendal blocks and three patients, mucosal anaesthesia.

All of these patients were relatively young men. Some of their greatest problems were created by psychosexual conflicts. Table 16 presents sexual data.

There were 76 patients or $66.6 \%$ who had erections of some kind. Of the remaining 38, 16 did not provide the appropriate information so that only $19.2 \%$ can assuredly be said to be impotent. Twenty-eight patients $(24.5 \%)$ were able to have relations. It is to be noted that many of our patients were interviewed when still hospitalised and in a debilitated condition so the percentage able to achieve relations may be higher.

Data regarding vocational rehabilitation are presented in Table 17.

Many patients developed a vocational plan while in the hospital which frequently changed on release. For this reason the patient was placed in the unknown group unless it was specifically known at the time of the study with what the patient was vocationally involved. Twenty-nine patients $(25.4 \%)$ were enrolled at college and nine $(7.8 \%)$ were gainfully employed. Thirty-five $(30.7 \%)$ were as yet hospitalised. Some patients required one year or more before they made definite vocational plans.
To complete our observations Table 18 presents data regarding length of hospital stay.

Eighty-five patients only are included in 'VAHLB' and 'Total Hospital Stay' of Table 18. Twenty-six patients still hospitalised at the time of study are not included. Three patients were treated primarily at other spinal cord injury centres and were transferred to VAHLB. These are not included.

\section{Mortality}

There were two deaths, one 4 months post-injury of meningitis and pneumonia and the other 1 year and 7 months post injury of pneumonia. Both patients had cervical cord lesions.

\section{Discussion}

\section{Age of patients}

In combat paraplegics the age at injury is younger than in other groups be they military or civilian. All of our patients were under 40 years and $70 \%$ (80 patients) were under 24 years. In cases of non-combat or civilian injuries the age among a sample of 153 patients was found to be considerably older. One hundred and twenty-one patients $(79 \%)$ were under 40 years of age and $37(24.1 \%)$ under 24 years of age at time of injury. It has been shown that the younger the patient at injury the better the prognosis for survival and rehabilitation (Nyquist and Bors, 1967).

Level and extent of lesion: In our series $13.1 \%$ were cervical injuries; $22.8 \%, \mathrm{~T} 1-\mathrm{T} 6 ; 31.5 \%, \mathrm{~T} 7-\mathrm{T} 12$; and $32.3 \%, \mathrm{~L}-\mathrm{S}$ injuries. In a series of 1884 patients reported by Nyquist and Bors (1967) $29.8 \%$ were cervical; $16.6 \%$, T1-T6; 35.2\%, T7-T12; and L-S, 7.4\% This included both combat and non-combat injuries. The L$\mathrm{S}$ group shows great variance which can be explained by the difference in the mechanism of injury. The combat injuries are largely the result of bullet wounds the rifleman aiming for the largest area or shell fragments with the fragment displaced upward from ground level. In non-combatants the lower parts of the spine are rarely exposed to direct impact of a force except in falls from great heights or direct hits by a falling object.

In another series of 233 patients reported by Bors (1956) cervical cord lesions were caused by gunshot in $8.6 \%$ and by other violent trauma (excluding auto accidents, diving, and falls) in $9.4 \%$ The total $18 \%$ compares with the $13.1 \%$ of Table 2 . In contrast is the 
Table 15 Delayed intermittent catherterisation

\begin{tabular}{|c|c|c|c|c|c|c|c|c|c|c|c|c|}
\hline & \multirow{2}{*}{$\begin{array}{l}\text { Length cath. } \\
\text { was in place } \\
\quad \text { (days) }\end{array}$} & \multirow[b]{2}{*}{$0-15$} & \multicolumn{2}{|c|}{$\begin{array}{l}\text { Time of inter. cath. } \\
\text { (days) }\end{array}$} & \multirow{2}{*}{$60-90$} & \multirow[b]{2}{*}{ Succ. } & \multirow[b]{2}{*}{ Unsucc. } & \multirow[b]{2}{*}{ Regression } & \multicolumn{2}{|c|}{$\begin{array}{l}\text { Urine } \\
\text { C. \& S. prior }\end{array}$} & \multicolumn{2}{|c|}{$\begin{array}{l}\text { Urine } \\
\text { C. \& S. after }\end{array}$} \\
\hline & & & $15-30$ & $30-60$ & & & & & pos. & neg. & pos. & neg. \\
\hline C com & $\begin{array}{c}101,123,122 \\
68,87\end{array}$ & 1 & - & - & 2 & 3 & 2 & - & 5 & - & 4 & 1 \\
\hline $\begin{array}{l}\mathrm{C} \text { incom. } \\
\mathrm{T} 1-\mathrm{T} 6 \\
\text { com. }\end{array}$ & $\begin{array}{c}- \\
104,202,146 \\
135,151,98\end{array}$ & - & - & - & - & - & - & - & - & - & - & - \\
\hline $\mathrm{T} 1-\mathrm{T} 6$ & $185,293,102$ & 2 & 2 & 3 & 1 & 8 & 1 & 1 & 9 & - & 8 & 1 \\
\hline $\begin{array}{l}\text { incom. } \\
\text { T7-T12 } \\
\text { com. }\end{array}$ & $\begin{array}{c}99,360 \\
94,112,114 \\
98,118,148\end{array}$ & 1 & - & - & - & 1 & - & - & 2 & - & 1 & - \\
\hline $\mathrm{T} 7-\mathrm{T} 12$ & 141, 71 & 3 & 2 & 1 & 1 & 7 & 1 & 2 & 6 & 2 & 5 & 3 \\
\hline $\begin{array}{l}\text { incom. } \\
\text { *L-S }\end{array}$ & - & - & - & - & - & - & - & - & - & - & - & - \\
\hline $\begin{array}{l}\text { com. } \\
\text { L-S }\end{array}$ & $170,200,120$ & - & 1 & 1 & 1 & 3 & - & - & 3 & - & 2 & - \\
\hline incom. & 77 & - & - & 1 & - & 1 & - & - & 1 & - & - & 1 \\
\hline
\end{tabular}

Table 16 Sexual data

\begin{tabular}{|c|c|c|c|c|c|}
\hline & \multicolumn{2}{|c|}{ Erection } & \multirow[b]{2}{*}{ Nil } & \multirow[b]{2}{*}{ Relat. } & \multirow[b]{2}{*}{ Ejac } \\
\hline & Psychic & Reflex & & & \\
\hline C com. & - & 8 & 1 & 2 & - \\
\hline $\mathrm{C}$ incom. & 3 & 3 & - & 2 & - \\
\hline T1-T6 com. & - & 12 & 3 & 4 & - \\
\hline T1-T6 incom. & 3 & 3 & - & 3 & - \\
\hline T7-T12 com. & 2 & 11 & 11 & 7 & - \\
\hline T7-T12 incom. & 4 & 5 & - & 1 & - \\
\hline L-S com. & 14 & 5 & 5 & 5 & 3 \\
\hline L-S incom. & 8 & 2 & 3 & 4 & 1 \\
\hline
\end{tabular}

$29.8 \%$ cervical injuries noted above. This variation is due to the fact that they are largely automobile and diving accidents.

In this combat series $79(69 \%)$ had complete and 35 $(31 \%)$ incomplete lesions. In the large series of Nyquist and Bors (1967) 1135 (65\%) had complete and $716(35 \%)$ had incomplete lesions. These percentages are similar.

\section{Mechanism of injury}

Fifty-seven $(50 \%)$ of our patients were injured by a bullet wound. This was usually by sniper fire or ambush. This would attest to a degree of success of this means of attack. Claymore mines caused injury by direct shell fragment or by blast effect and were the next most common mode of injury. Friendly fire accounted for three bullet injuries.

The mechanisms of injury in combat are haphazard, not following any pattern as compared with civilian injuries. In this latter the cervical lesions are caused by automobile or diving mishaps, ie cervical flexion or hyperextension. Direct trauma, ie thrown from vehicle,
Table 17 Vocational rehabilitiation

\begin{tabular}{lccrcc}
\hline & & & \multicolumn{3}{c}{ Still } \\
& School & Work & Nil & hospitalised & Unknown \\
\hline C & 2 & 2 & 4 & 7 & - \\
T1-T6 & 10 & 2 & 4 & 7 & 3 \\
T7-T12 & 8 & 2 & 10 & 10 & 6 \\
L-S & 9 & 3 & 9 & 11 & 5 \\
Total & 29 & 9 & 27 & 35 & 14 \\
\hline
\end{tabular}

fall from a height, 'jackknifing' in mine or under a car, or direct blow, account for lesions at other levels.

Additional injury, non-G.U.

The fact that $67 \%$ of patients had major injury in addition to the spinal injury and survived eventually to reach a spinal injury centre attests to the quality of emergency care. The time period from injury to evacuation to a field hospital or hospital ship is said to average 1h; from field hospital to evacuation hospital averages 1 day; from evacuation hospital to active therapy in the US or Japan only 3 days (Busch et al 1967). Evacuation during World War II was much less rapid. The extensive use of helicopter rescue services and air evacuation have been responsible for this change.

Chest injuries (all resulting in hemopneumothorax) occurred in 43 patients; 35 of these had T1-T2 injuries as is expected. Of 18 gastro-intestinal tract wounds 13 were in patients with lumbosacral lesions.

Additional injuries, G.U.

There were 16 kidney injuries severe enough to demand exploration. In five additional patients haematuria occurred but the exact source could not be defined. 
Table 18 Hospitalisation time

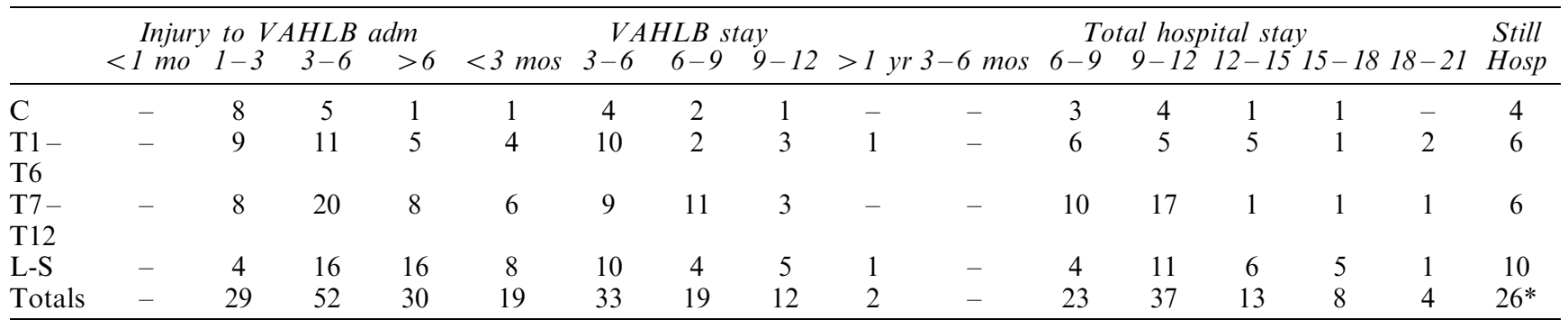

*The difference between the figures in the text of 35 patients 'Still hospitalised' against 26 patients 'Still hospitalised'shown in Table 18 is caused by readmission of nine patients for checkup examination

The incidence of renal injury is $12.2 \%$ (14 patients). To contrast, Busch's series of 370 patients had $2.7 \%$ (10 of 370) renal injuries (Busch et al 1967), and in 1096 patients reported by Oschener et al. (1969) $2.4 \%$ (27 of 1096) had renal injuries. Both of the above series contained patients without spinal cord involvement. This would indicate a greater severity of injury in our patients.

The 16 renal injuries were treated by nephrectomy in eight instances; partial nephrectomy in one; and in seven, debridement and drainage. In Oschener's series of 27 there were eight nephrectomies; one partial nephrectomy; four suture repair; and 14 debridement and drainage. In Salvatierra's series of 79 renal injuries (1969) 10 were managed by bed rest; 28 by debridement and drainage; six by partial nephrectomy; and 35 nephrectomies were done. The management of renal injury does not vary due to the spinal cord involvement.

\section{Ureteral injury}

The well-known fact that trauma per se rarely causes ureteral injury is again shown in that only one patient suffered a ureteral wound.

\section{Bladder injury}

The one bladder injury was treated in the conventional way by insertion of suprapubic tube, repair and perivesical drainage.

\section{Laminectomy}

There is general agreement regarding the necessity of laminectomy in compound injury, $94.7 \%$ of our patients underwent laminectomy. Ninety or $78.9 \%$ of patients sustained compound injuries. Conversely there is great controversy in regard to the indications for laminectomy in closed spinal cord trauma. Six closed injuries $(5.3 \%)$ did not have laminectomy. This leaves a group of 17 patients where laminectomy for closed injury was performed. Bony deformity, manometric block, failure to recover function were the indications. The results regarding degree of recovery in this group cannot be analyzed due to lack of precise neurological data.

Complications, non-G.U.

Well-known phantom sensations were extremely common but were not studied in each patient. Dissociation was observed to last for six or more months following incomplete cervical cord lesions with additional brachial plexus lesions and lacked correction by visual control, so that reduplication of one upper extremity was experienced.

Pain was reported in 19 patients with upper motor neuron lesions and 31 with lower motor neuron lesions. It often abated with time and with progression of rehabilitation. Acute complications (G.U. usually) often caused an exacerbation to the discomfort which abated with successful therapy. Hypnosis was useful in selected patients. In the entire series no cordotomy or rhizotomy has been performed (Porter et al 1966).

Autonomic dysreflexia of varying severity can be provoked by an appropriate stimulus in all lesions above the splanchnic outflow (Guttmann and Whitteridge, 1947; Bors and French, 1952). Of 15 patients with cervical lesions (10 complete, five incomplete) this was a problem in four patients. In 26 patients with $\mathrm{T} 1$ - T6 levels (19 complete, seven incomplete) this was a problem in two cases. The acute episode was managed by elevation of the head of the bed and bladder drainage. If a distended rectum was the inciting cause, this was emptied. If these were not successful, mucosal anaesthesia (as described previously) was utilised. Etamon (tetraethyl ammonium chloride), a ganglionic blocking agent, was used. Patients in whom this was a frequent problem were placed on Ansolysen (pentolinium tartrate). In no patient was it necessary to consider spinal block either as a temporary or more permanent (alcohol) measure.

\section{Complications related to general surgical trauma}

The gastro-intestinal haemorrhages that occurred (four patients) were all serious and believed related to stress ulcers. 
Gram-negative sepsis was documented by blood cultures in three patients. All occurred prior to admission to the Long Beach VA Hospital.

Cardiac arrest (three patients) occurred during anaesthetic induction for further surgery in the early post-injury period. One patient arrested on two occasions under these circumstances and showed signs of transient cerebral damage with recovery.

Bowel obstruction was due to volvulus (small bowel) in one patient and adhesions in three patients. All had undergone laparotomies immediately post-injury.

Deafness occurred in a patient being treated for a urinary tract infection with Kanamycin.

Diabetes was found 6 months post-injury in a patient of Hawaiian ancestry with no family history.

Gynaecomastia occurred in two patients $(1.7 \%)$ which contrasts with $10.2 \%$ reported by Bors (1948) in World War II patients. Klatskin, Salter and Humm (quoted by Bors, 1948) did not find an abnormality of estrogen or other steroid production but suspected a temporarily deficient inactivation of estrogen in the liver.

Thrombophlebitis involving the lower limbs was recorded in seven patients; five of these had upper motor neuron lesions (T6, T7, T9, T10, L1), and two had lower motor neuron lesions (T6, L3). The number is small but does not agree as regards frequency in lower motor neuron lesions as opposed to upper motor neuron lesions when examined with phlebography (Bors et al 1954). All occurred in the early post-injury period. All of the above were diagnosed clinically and not by phlebograms. One patient developed a pulmonary embolus in whom no clinical thrombophlebitis could be demonstrated.

\section{Complications G.U.: Calculosis}

Munro (1948) in a report of 101 World War II soldiers found in $14.0 \%$ incidence of renal calculi. Bunts (1967) in his World War II group reported $13 \%$ at 1 year decreasing to $8 \%$ at 4 years; however, in his Korean war group the incidence was $5 \%$ during the first 4 years of follow-up. Bors (1951) in a series of 354 World War II wartime injuries reported an incidence of $15.5 \%$ Our finding of $13 \%$ correlates with all except for the Korean group of Bunts (1967). All calculi were treated by means of renacidin infusions by ureteral catheters with the exception of three that dropped into the ureter. Data on this method of therapy are being evaluated. All of these calculi occurred within 2 years of injury. All but two patients had accompanying injuries of variable magnitude, which may be important.

\section{Infection}

There was no attempt to define the incidence of upper urinary tract infection in our patients. Lower urinary tract infection was more clearly documented with 21 patients $(19.8 \%)$ achieving a sterile urine at time of discharge or on latest culture. Eighty-five patients $(80.2 \%)$ were infected by the same criteria. Three of the 21 had been managed by intermittent catheterisation and the remainder were catheter free. Many of these patients had incomplete lesions. Proteus (rettgeri, vulgaris, mirabilis, morgagni) was present in $75.2 \%$ of the infected urines. There was no attempt to sterilise the urine when a patient was on catheter drainage by means of antibiotics. Our patients were maintained on high doses of vitamin $\mathrm{C}$ and Mandelamine (methenamine mandelate) in association with a high fluid intake. Antibiotics were relegated for treatment of special cases of acute clinical infection and accompanied by highvolume intravenous fluids.

\section{Hydronephrosis}

Twenty kidneys (11 right and nine left) developed varying degrees of hydronephrosis on IVP. Most cases were accompanied by ureterectasis. Fourteen were in patients with lower motor neuron lesions and six were in patients with upper motor neuron lesions. All occurred in patients who were catheter free; two (left side) were associated with renal calculosis. In 63 patients with upper motor neuron lesions (126 kidneys) six kidneys developed hydronephrosis $(4.7 \%)$, while in contrast in 51 patients with lower motor neuron lesions (94 kidneys) 14 kidneys became hydronephrotic (14.8\%). Two kidneys (one left, one right) have returned to a normal IVP configuration on catheter drainage. One kidney remains unchanged, and in 10 it is too early to evaluate. In no instance could anatomic obstruction be demonstrated (ie ureteral catheters passed readily). The exact mechanism is unknown but further evaluation by cine studies is planned. It is of special interest that $14 / 20(70 \%)$ occurred in balanced lower motor neuron bladders many of which showed severe changes on cytoscopy.

Pathological changes at the penoscrotal (PS) junction: In our patients $8.8 \%$ developed pathological changes at the P-S junction with six (5.2\%) progressing to fistula formation. In a World War II series of 354 patients Bors (1951) reported 3.1\% incidence of fistula formation. A peacetime group of 269 patients at the same time had developed fistula in $11.9 \%$ The wartime groups' low figure can be attributed to the fact that suprapubic cystostomy was almost routinely performed in paraplegics during World War II. Diverticula were found in $48.4 \%$ of Bors' series (1951) while only three patients $(2.1 \%)$ of our series showed this. Urethrograms were done only for specific indications in our present series; thus our percentage may be higher than $2.1 \%$ In the above quoted patients with an incidence of $48.4 \%$ routine urethrograms were done and the follow-up period was longer. None of our patients treated with intermittent catheterisation has developed penoscrotal pathology, which again reiterates Guttmann's (1966) experience. 
'Pseudopapillomata'

Papillary excresences were found in the bladder in three instances $(2.6 \%)$ and urethra in four instances $(3.5 \%)$. In the latter group two lesions were reported as squamous carcinoma. Therapy consisted of excisional biopsy (where possible) and fulguration. The catheter (present in all patients) was changed to a smaller size or to a plastic catheter. Silver nitrate (1:10 000 to $1: 1000)$ irrigations were done. The two patients reported as having squamous carcinoma of the urethra are both doing well under close scrutiny. In a review of 2046 patients Shey and Bors (1966) found the incidence of vesical papillomata to be $7.9 \%$ and urethral $1.6 \%$ They noted infection and the presence of a catheter to be the probable inciting causes both of which were present in our cases.

\section{Suprapubic cystostomy}

A suprapubic tube was present on admission to the Long Beach VA Hospital in five patients. In two instances cystostomy was emergent in treating a ruptured bladder; in one instance it was iatrogenic. One patient had a tube placed for urethritis; one for spasms and one for a P-S fistula. In treating urethritis we recommend the use of a smaller or of a plastic catheter. Spasms in our experience are not an indication for suprapubic cystostomy which may often aggravate them. In the past it has been rarely necessary to use a suprapubic diversion to achieve a closure of a P-S fistula. In patients with lower motor neuron lesions it is contra-indicated as urine will continue to leak via the bladder outlet. Our suggested indications for suprapubic cystostomy are: (a) ruptured bladder, (b) severe impassable urethral stricture, and $(c)$ subtrigonal diverticulum making catheter insertion very difficult. The last condition can be occasionally treated by a transurethral deroofing procedure.

\section{Urological rehabilitation}

Reference to Table 12 will show that the percentage of catheter free patients at the time of this study was within an $11 \%$ range for all lesion levels $(67 \%$ for cervical to $78 \%$ for low thoracic lesions). The level of the lesion does not seem to affect the chance of achieving a catheter-free state. The chance of reaching this goal was enhanced by incompleteness of the lesion (Comarr, 1959).

Reference to Table 13 will show that the largest number of our patients developed a 'balanced' bladder between 3 and 6 months post-injury (35) and 6 and 9 months (26). This correlated with previous experience at this centre. It is of interest that with the use of early intermittent catheterisation Hardy (1966) found 13 of 17 patients to develop balanced bladder function within 3 months after injury. This experience was similar to that reported by Guttmann (1966) in a larger group. Our patients did not have the advantage of early intermittent catheterisation, but it is our impression that even in individuals with delayed intermittent catheterisation balanced bladder function is facilitated. In contradistinction to Guttman's (1966) series only four of 28 patients developed sterile urine on intermittent catheterisation; however, these series are not strictly comparable as our patients arrive with well-established lower urinary tract infections as this procedure cannot be used in the field and the Foley catheter is used rather than the Gibbon.

\section{Sexual data}

There was some difficulty accurately interpreting patients' statements in regard to psychic and reflex erections. The presence of pseudo-spontaneous erections, reflex in nature, were occasionally interpreted by the patient as psychic.

At all levels patients with incomplete lesions reported psychic erections.

Two patients with flaccid paralysis and dermatome levels below T11 and T12, respectively, had psychogenic erections. It is possible that cholinergic impulses are conveyed by the hypogastric nerves to explain the psychic erections. In the low thoracic (T7-T12) group, 11 patients reported no erections. Most of these had lower motor neuron lesions. In the L-S complete group, five patients noted reflex erections: three had epiconal lesions, the other two had lower motor neuron lesions. Marburg and Ranzi (quoted by Jelliffe and White Text of Neurology) claim that reflex erections are possible under these circumstances based upon an alleged peripheral reflex mechanism. One patient with a complete L3 epiconal lesion noted both psychic and reflex erections. Although this is exceptional it has been noted (Bors and Comarr, 1960).

Sixteen of 38 patients with clinically complete lower motor neuron lesions 'claimed' psychic erections $(42.1 \%)$. This is higher than the $27 \%$ reported by Bors and Comarr (1960). In this group ejaculation occurred in four instances $(10.5 \%)$. In all instances it was the typical dribbling emission. This compares with $19 \%$ in a similar group in the above quoted series.

\section{Vocational rehabilitation}

Reference to Table 17 shows that of a total of 114 patients 35 are yet hospitalised and in 14 the activity status is not accurately known. This leaves 38 patients actively engaged at school or work while 27 patients are inactive. It furthermore illustrated that in this group of young people the preference of school over work is better than $3: 1$. Further analysis of the table shows that at all lesion levels the distribution between active and inactive patients is about the same. Motivation for schooling is markedly enhanced by government support extended to these patients.

\section{Hospitalisation time}

Reference to Table 18 shows that no patient was admitted to our facility within 1 month of injury; 
$26.1 \%$ from $1-3$ months; $46.8 \%$ from 3 to 6 months; and $27.1 \%$ over 6 months. Many of this last group were over 1 year post-injury. There is an obvious hold up at armed forces hospitals which in many cases seemed undesirable. The speed of delivery of patients to the Spinal Cord Injury Centre is in sharp contrast to the speed of emergency care and evacuation previously alluded to. We are aware that combat injuries cannot be transferred in the early post-injury period in the same way as civilian injuries as reported by Cheshire (1967), where $70 \%$ were received within $48 \mathrm{~h}$.

In regard to length of stay at our facility, $22.3 \%$ were discharged within 3 months; $61.1 \%$ within 6 months. Only $2.3 \%$ were hospitalised over 1 year. This is in sharp contrast with our past experience with World War II and the Korean conflict when hospitalisation at this centre averaged 18 months for paraplegics and 24 months for quadriplegics. This would suggest that the experience gained over 20 years has contributed to more security and less selfconsciousness of the patient, both of which may have been the cause of delayed discharge in World War II patients. Society has learned to accept these patients and the patients have met the challenge of competition with non-paraplegics.

Eighty-five patients have completed their primary hospitalisation. In regard to total length of hospitalisation (date of injury to discharge from spinal cord injury centre), 23 patients $(27 \%)$ required 6-9 months; $37(43.5 \%)$ required $9-12$ months; 25 $(29.5 \%)$ required over 1 year of hospital care. This again reflects a shorter hospital stay than was our experience with World War II or Korean patients.

\section{Mortality}

The mortality over the short follow-up period was $1.7 \%$ It must be stressed that mortality figures for a chronic disorder, such as spinal cord injury, are meaningless unless a long period of follow-up is utilised (Nyquist and Bors, 1967). It is not surprising that renal pathology was not the cause of death as it is recognised that renal deterioration of lethal degree rarely occurs in paraplegics under 5 years.

\section{Summary}

Observations on 114 Vietnamese combat injuries with spinal cord involvement treated from December 1965 to April 1969 are presented. Eighty $(70 \%)$ of patients were under 24 years of age and $11(9.6 \%)$ over 30 years; there were $79(68 \%)$ clinically complete and 35 $(31 \%)$ incomplete lesions; 61 patients had UMN lesions and 53 patients had LMN lesions. Fifty-seven patients received their injury by bullet wounds, the remainder largely by shell fragment, blast, or vehicle crash. Sixty-seven $\%$ of patients had multiple injuries with 43 chest injuries and 18 patients sustained gastrointestinal tract wounds. There were 16 renal injuries, one ureteral laceration and one ruptured bladder.
Emergency therapy was rapidly performed in wellequipped hospitals. Evacuation was markedly enhanced by helicopter service. The renal injuries resulted in eight nephrectomies, one partial nephrectomy, and seven repairs with drainage. One hundred and seven patients underwent laminectomy, 90 for compound injuries.

During the follow-up period G.U. complications found were: renal calculosis in 14 patients $(13 \%)$; hydronephrosis in 20 patients $(11.4 \%$ of kidneys in patients with LMN lesions, $4.7 \%$ of kidneys in patients with UMN lesions); lower urinary tract infection in 85 patients $(80.2 \%)$; epididymitis in 14 patients $(12.8 \%)$; PS pathology in 10 patients $(8.8 \%)$; 'pseudopapillomata' in seven patients (three bladder, four urethra); bladder calculi in 56 patients $(49.1 \%)$. Decubit and pain were frequent problems. Pain was treated by non-operative means.

In regard to urological rehabilitation $67 \%$ to $78 \%$ (varying with lesion level) were catheter-free at the time of study with $53.5 \%$ of patients achieving this by 9 months post-injury. The procedures necessary to achieve this, including delayed intermittent catheterisation, are presented.

Seventy-six patients $(66.6 \%)$ had erections and 28 $(24.5 \%)$ have been able to have relations. $42.1 \%$ of patients with clinically complete lower motor neuron lesions claimed psychic erections.

At the time of the study 29 patients have returned to school and nine to gainful employment; 35 patients are still hospitalised and 27 are vocationally inactive. This did not vary with the lesion level.

The length of hospitalisation is presented and contrasted with that of World War II and Korean paraplegics. $61.1 \%$ of patients required under 6 months of care at a spinal cord injury centre and only $29.4 \%$ ( 25 patients) required over 1 year of total hospitalisation.

\section{References}

Bors E. (1948). Veterans Administration Technical Bulletin, TB $10-503$.

Bors E. (1951). Journal of the American Medical Association, 146, 225.

Bors E. (1956). Bulletin of the Los Angeles Neurological Society, 21, 105.

Bors E. (1964). Journal of the International College of Surgeons, 42, 22.

Bors E. \& Comarr AE. (1960). Urological Survey, 10, 191.

Bors E, Conrad CA \& Massell TB. (1954). Surgery Gynecology and Obstetrics, 99, 451.

Bors E \& French JD. (1952). Archives of Surgery, 64, 803.

Busch FM, Chenault OW, Zinner NR \& Clarke BG. (1967). Journal of Urology, 97, 763.

Cheshire DJE. (1967). Clinical Spinal Cord Injury Conference Proceedings, p. 39.

Comarr AE. (1959a). British Journal of Urology, 31, 1.

Comarr AE. (1959b). Journal of Urology, 81, 537.

Comarr AE., Kawaichi, G. \& Bors, E. (1962). Journal of Urology, 85, 647. 
Guttmann L \& Frankel H. (1966). Paraplegia, 4, 63

Guttmann L \& Whitteridge D. (1947). Brain, 70, 361.

Hardy AG. (1966). Medical Services Journal, Canada, 538.

Head H \& Riddoch J. (1917). Brain, 40, 188.

Michaelis LS. (1968). Paraplegia, 6, 46.

Munro D. (1948). American Journal of Surgery, 75, 3.

Nyquist RH \& Bors E. (1967). Paraplegia, 5, 22.

Ochsner TG, Busch FM \& Clarke BG. (1969). Journal of Urology, 101, 224.
Porter RW, Hohmann GW, Bors E \& French JD. (1966). Archives of Surgery, 92, 765.

Salvatierra OJ, Rigdon WO, Norris DM \& Brady TW. (1969). Journal of Urology, 101, 615.

Shey HH \& Bors E. (1966). Urologia internationalis, 21, 253.

Wadewitz P, Langois PJ \& Bunts RC. (1967). Journal of Urology, 98, 706. 